\title{
Predictors of long-term HRQOL following cardiac surgery: a 5-year follow-up study
}

\author{
Daiva Grazulyte ${ }^{1}$, leva Norkiene ${ }^{1}$, Evaldas Kazlauskas ${ }^{2 *}$ (D) Inga Truskauskaite-Kuneviciene ${ }^{2}$, \\ Smilte Kolevinskaite ${ }^{1}$, Donata Ringaitiene ${ }^{1}$ and Jurate Sipylaite ${ }^{1}$
}

\begin{abstract}
Background: The study aimed to evaluate the long-term change of health-related quality of life (HRQOL) and to identify predictors of HRQOL 5 years after cardiac surgery.

Methods: Consecutive adult patients, undergoing elective cardiac surgery were enrolled in the study. HRQOL was measured using the Medical Outcomes Study 36-Item Short-Form Health Survey (SF-36) questionnaire before and 5-years after cardiac surgery. A multivariate latent change modeling approach was used for data analysis.

Results: 210 participants (30.5\% female) were reached at 5-year follow-up and included in final data analysis. The study revealed, after controlling for gender effects, a significant long-term positive change, in physical functioning $\left(P F, M_{\text {slope }}=19.79, p<0.001\right)$, social functioning ( $\left.S F, M_{\text {slope }}=17.27, p<0.001\right)$, vitality $\left(V T, M_{\text {slope }}=6.309, p<0.001\right)$ and mental health $\left(\mathrm{MH}_{1} \mathrm{M}_{\text {slope }}=8.40, p<.001\right)$ in the total sample. Lower education was associated with an increase in PF $\left(\mathrm{M}_{\text {slope }}=24.09, p<0.001\right)$ and $\mathrm{VT}\left(\mathrm{M}_{\text {slope }}=8.39, p<0.001\right)$, more complicated surgery (other than the coronary artery bypass graft $(\mathrm{CABG})$ predicted increase in general health $\left(\mathrm{GH}, \mathrm{M}_{\text {slope }}=6.76, p=0.005\right)$. Arrhythmia was a significant predictor for lower pre- and post-operative VT and SF.
\end{abstract}

Conclusions: Overall HRQOL in our sample improved from baseline to five years postoperatively. Further studies including larger patient groups are needed to confirm these findings.

Keywords: Cardiac surgery, Health-related quality of life, Risk factors, Long-term

\section{Introduction}

Improving or sustaining Health-related quality of life (HRQOL) is one of the main objectives of modern healthcare. HRQOL incorporates the physical, psychological, and social domains of wellbeing as well as the effects of illness and treatment applied [1]. HRQOL as a measurable outcome is often considered to be one of the most important indicators of advancements in healthcare and disease management resulting in increased life

\footnotetext{
*Correspondence: evaldas.kazlauskas@fsf.vu.lt

${ }^{2}$ Centre for Psychotraumatology, Institute of Psychology, Vilnius University, Vilnius, Lithuania

Full list of author information is available at the end of the article
}

expectancy of those living with chronic health conditions. Moreover, the American Heart Association (AHA) recently defined HRQOL as the "discrepancy between actual and desired functional status and overall impact of health on well-being" and included HRQOL evaluation as a strategic treatment goal for cardiovascular health [2].

Due to its complexity and the aging population, cardiac surgery was always a subject where such outcomes as the rates of postoperative morbidity and mortality were qualified as sufficient in estimating the result of the treatment [3]. Over the last decades, measurement of health outcomes became as important as the patient's ability to fulfill their psychological, and social original author(s) and the source, provide a link to the Creative Commons licence, and indicate if changes were made. The images or other third party material in this article are included in the article's Creative Commons licence, unless indicated otherwise in a credit line to the material. If material is not included in the article's Creative Commons licence and your intended use is not permitted by statutory regulation or exceeds the permitted use, you will need to obtain permission directly from the copyright holder. To view a copy of this licence, visit http://creativecommons.org/licenses/by/4.0/. The Creative Commons Public Domain Dedication waiver (http://creativeco mmons.org/publicdomain/zero/1.0/) applies to the data made available in this article, unless otherwise stated in a credit line to the data. 
needs after the cardiac surgery. Therefore, the monitoring of patients' HRQOL became one of the strategies to address the holistic concept of health in medical research with the Short-Form Health Survey (SF-36) being among the most popular ways to do it [4]. Heart surgery performed on asymptomatic or mildly symptomatic patients does not usually offer direct or immediate results that can be experienced by an individual. Some patients report lower levels of HRQOL following medical procedures, due to postoperative pain, sleep disturbance, memory problems, and disrupted social interactions by the surgery [5]. On the other hand, among patients with advanced heart failure, surgical treatment might decrease or eliminate symptoms, and significantly improve physical functioning and decrease need for pharmacotherapy, leading to an improvement in overall wellbeing and quality of life [6].

Long-term HRQOL after cardiac surgery or other medical procedures is determined not only by objective changes in health status but by personality and individual behavioral, cognitive, and emotional processes which contribute to adjustment to the changes in health status [7]. Assessment of the long-term HRQOL could provide an insight into how medical procedure or treatment is affecting the psychosocial functioning of the patient over time. Focusing on the patient-centered long-term HRQOL outcome measurements could shift treatment and rehabilitation goals towards multidisciplinary care aimed at improving the overall wellbeing of patients [8]. Recent findings on long-term HRQOL after cardiac surgery are inconsistent and often contradictory. Some studies aimed at investigating the change in HRQOL at one-year follow-up reported improvement in HRQOL while other studies failed to identify any change in HRQOL [5, 9]. Furthermore, few recent studies have explored HRQOL following cardiac surgery at 5 years follow-up or more $[3,10]$ with promising findings of sustained HRQOL many years after the surgery. Thus, more research addressing long-term HRQOL after cardiac surgery is needed [11].

The present study aimed to evaluate change in HRQOL after 5 years among patients who underwent elective cardiac surgery. Based on previous studies $[3,10]$, we expected to identify improvement in physical, psychological and social HRQOL outcomes at five years followup after the cardiac surgery. Furthermore, we aimed to estimate the role of multiple clinical and psychosocial indicators of long-term HRQOL after cardiac surgery, in particular, dyslipidemia, arrhythmia, hypertension, reduced left ventricular ejection fraction, EuroScore II, type of surgery, age, and education level. We expected these factors to represent the risk of failure to improve the long-term HRQOL after the cardiac surgery.

\section{Methods}

\section{Patients and data acquisition}

In a single-center prospective design study, all consecutive patients undergoing elective cardiac surgery from March of 2013 to April of 2014 at Vilnius University Hospital Santaros clinics were enrolled in a study. Three types of heart surgery were performed: coronary artery bypass grafting (CABG), valve surgery, and complex surgery. Inclusion criteria: patient age $\geq 18$ years, Lithuanian language proficiency, the level of cognitive functioning that enabled to respond to the study measures. The first (pre-operative) assessment was performed after admission, prior to surgery. The second assessment was performed via telephone survey 5 years after the surgery. We used five attempts to reach each patient at a 5-year follow-up at various times throughout the day in a twoweek period, with one extra call on consecutive 4 weeks. In case of no response, the official records were additionally re-checked and consulted to obtain the patient's vital status (dead or alive). If the patient was alive and was not reached, he/she was considered as a non-responder and was excluded from the study. Only fully completed questionnaires were included in the analysis. There was no imputation of missing data at the item-level. The study was approved by the Regional Bioethics Committee. Written informed consent was obtained from each patient at inclusion.

\section{Sample characteristics}

Out of 286 patients enrolled in the study, 210 adults (30.5\% female, aged $19-84\left(M_{\text {age }}=62.29, S D_{\text {age }}=11.29\right.$ at the baseline) were reached at 5-year follow-up and were included in data analysis. Excluded from the analyses were 76 patients for the following reasons: declined to participate $(n=29)$, unreachable $(n=17)$, diseased prior to 5-year follow-up $(n=14)$, other reasons $(n=16)$ (See Fig. 1). Characteristics of the sample are presented in Table 1.

\section{Health-related quality of life}

The primary outcome measure was Health-related quality of life (HRQOL), measured using the Medical Outcomes Study 36 Item Short Form Health Survey (SF $\neg 36$ ) questionnaire before and 5 years after cardiac surgery [12]. The SF-36 comprises 36 items used to measure 8 domains of health: general health $(\mathrm{GH})$, physical functioning $(\mathrm{PF})$, bodily pain $(\mathrm{BP})$, mental health $(\mathrm{MH})$, role limitations due to physical problems (RP), role limitations due to emotional problems (RE), vitality (VT), and social functioning (SF). Scores of each subscale range from 0 to 100 with higher scores indicating better HRQOL. The SF-36 has been previously used for assessing the HRQOL of cardiac patients in Lithuania [13]. 

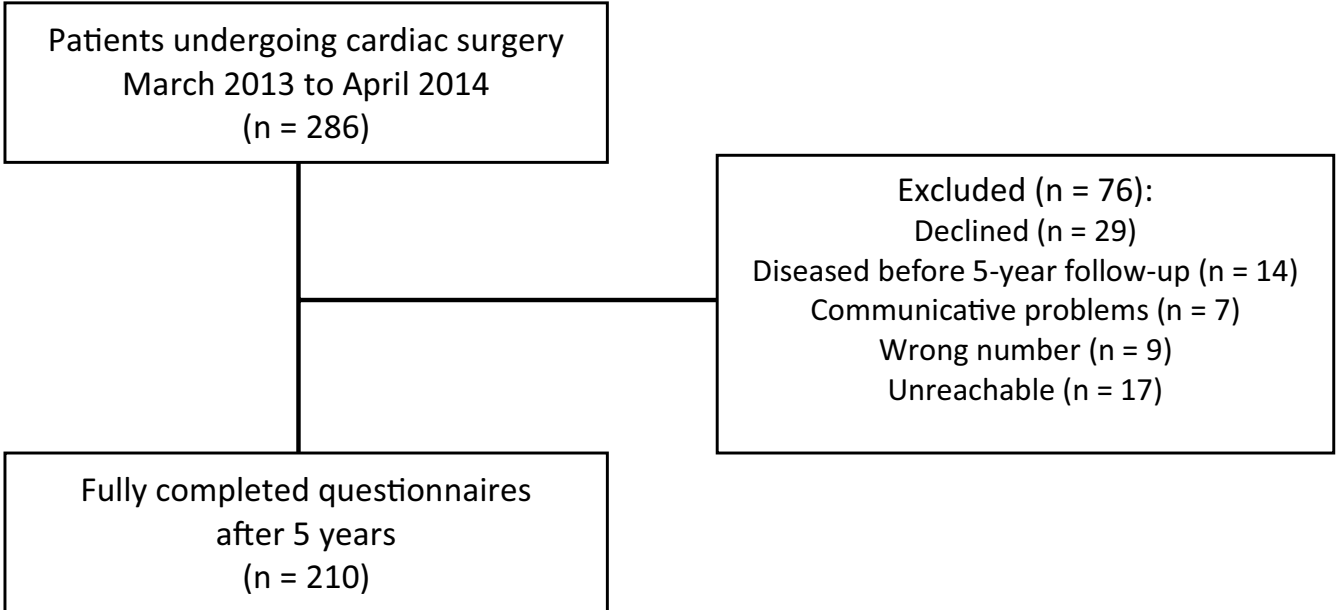

Fig. 1 The flow of the study

\section{Clinical and socio-demographic data}

For all patients, we collected data on sex, age, relationship status, area of residence (rural vs urban), employment status, level of education, comorbidities (dyslipidemia, arrhythmias, arterial hypertension, left ventricular ejection fraction in \%), and type of surgery. New York Heart Association (NYHA) classification, European system for cardiac operative risk evaluation (Euroscore II) [14] was used for assessment of all the patients. Medical and surgical information was collected from an institutional database.

\section{Statistical analysis}

To examine changes in the eight indicators of healthrelated quality of life (HRQOL) over five years after the cardiac surgery, in comparison to the pre-operative health condition, measured with the same eight indicators, we used a multivariate latent change modeling approach, that provides robust estimates of change over time [15]. We conducted a latent change model on eight parallel processes, in particular, general health $(\mathrm{GH})$, physical functioning (PF), bodily pain (BP), mental health $(\mathrm{MH})$, absence of role limitations due to physical problems (RP), absence of role limitations due to emotional problems (RE), vitality (VT), and social functioning (SF). In the current study, when testing the latent change model with two measurement points, the intercept represented the mean level of the HRQOL indicator at Time 1 (before the surgery) and the slope represented the change from Time 1 to Time 2 (5 years after the surgery).

As gender has been repeatedly shown to be a significant predictor of HRQOL $[16,17]$, in the latent change model, we controlled for gender effects on intercepts and slopes of all indicators. To have the latent change model identified, we fixed the residuals and the gender effects above marginal significance $(p>0.10)$ to zero, one by one, until we obtained the final model. Additionally, to identify whether the changes in health indicators were linked with one another and whether the initial levels of GH, PF, BP, MH, RP, RE, VT, and SF were associated with the changes in these indicators, we allowed the correlations between all intercepts and slopes.

After running the multivariate latent change model in the full study sample, we conducted a series of multiple group analyses by testing the preoperative risk factors, in particular, dyslipidemia, arrhythmia, hypertension (yes versus no), reduced left ventricular ejection fraction (LVEF $<50 \%$ versus normal $\mathrm{EF}>=50 \%$ ), and higher EuroScore II $(>=2 \%$ mortality risk versus $<2 \%$ low-risk group), type of surgery (coronary artery bypass graft only (CABG) versus valve type and complex) as well as psychosocial factors, namely, older age $(>=70$ years versus $<70$ years old) and higher education (yes versus no) as the moderators of baseline and change rates in HRQOL indicators. To assess possible differences between groups, we assessed differences between the models with fixed versus free parameters of slopes, indicating the same versus different levels of change in health indicators across the groups within moderators. Significant differences between the models with fixed versus free parameters were identified, when at least two of these three criteria were matched: $\Delta \mathrm{X}^{2}$ significant at $p<0.05$ [18], $\Delta$ CFI (the Comparative Fit Index) $\geq 0.01$, and $\triangle$ RMSEA (the Root Mean Square Error of Approximation) $\geq 0.015$ [19]. To test for differences in HRQOL indicators at Time 1 as well as to compare the change parameters across moderators, we ran the Wald $\chi^{2}$ tests. 
Table 1 Sample characteristics at pre-surgery and at 5-year follow-up $(\mathrm{N}=210)$

\begin{tabular}{|c|c|c|}
\hline & $n$ & $\%$ \\
\hline \multicolumn{3}{|l|}{ Sample characteristics at baseline } \\
\hline \multicolumn{3}{|l|}{ Gender } \\
\hline Female & 64 & 30.5 \\
\hline Male & 146 & 69.5 \\
\hline \multicolumn{3}{|l|}{ Age } \\
\hline$<70$ years & 157 & 74.8 \\
\hline$>=70$ years & 53 & 25.2 \\
\hline \multicolumn{3}{|l|}{ University degree } \\
\hline No & 146 & 69.5 \\
\hline Yes & 63 & 30.0 \\
\hline Not disclosed & 1 & 0.5 \\
\hline \multicolumn{3}{|l|}{ Dyslipidemia } \\
\hline No & 96 & 45.7 \\
\hline Yes & 114 & 54.3 \\
\hline \multicolumn{3}{|l|}{ Arrhythmia } \\
\hline No & 167 & 79.5 \\
\hline Yes & 43 & 20.5 \\
\hline \multicolumn{3}{|l|}{ Hypertension } \\
\hline No & 43 & 20.5 \\
\hline Yes & 167 & 79.5 \\
\hline \multicolumn{3}{|l|}{ Left-ventricular ejection fraction } \\
\hline Reduced $(<50 \%)$ & 74 & 35.2 \\
\hline Normal (>=50\%) & 130 & 61.9 \\
\hline No information & 6 & 2.9 \\
\hline \multicolumn{3}{|l|}{ EuroScorell } \\
\hline Higher mortality risk (>=2\%) & 59 & 28.1 \\
\hline Lower mortality risk (<2\%) & 151 & 71.9 \\
\hline \multicolumn{3}{|l|}{ Type of surgery } \\
\hline Coronary artery bypass graft (CABG) & 136 & 64.8 \\
\hline Other & 74 & 35.2 \\
\hline \multicolumn{3}{|l|}{ Sample characteristics at 5-year follow-up } \\
\hline \multicolumn{3}{|l|}{ Relationship status } \\
\hline In a committed relationship & 143 & 68.1 \\
\hline Not in a committed relationship & 65 & 31.0 \\
\hline Not disclosed & 2 & 1.0 \\
\hline \multicolumn{3}{|l|}{ Employment } \\
\hline Employed & 58 & 27.6 \\
\hline Unemployed & 75 & 35.7 \\
\hline Retired & 76 & 36.2 \\
\hline Not disclosed & 1 & 0.5 \\
\hline \multicolumn{3}{|l|}{ Residence area } \\
\hline Urban & 154 & 73.3 \\
\hline Rural & 55 & 26.2 \\
\hline Not disclosed & 1 & 0.5 \\
\hline
\end{tabular}

In all analyses, model fit was evaluated using the Comparative Fit Index (CFI), indicating the discrepancy between the data and the hypothesized model, the
Tucker-Lewis Index (TLI), indicating the discrepancy between the chi-squared value of the hypothesized model and the chi-squared value of the null model, and the Root Mean Square Error of Approximation (RMSEA), indicating the discrepancy between the hypothesized model, with optimally chosen parameter estimates, and the population covariance matrix. When evaluating the model fit, we followed the goodness of fit recommendation provided by [20]. In particular, CFI/TLI values higher than 0.90 indicate an acceptable fit, and values higher than 0.95 represent a very good fit; RMSEA values below 0.08 indicated an acceptable fit, and values less than 0.05 suggested a good fit. The analyses were conducted with Mplus 8.2 by using the robust maximum likelihood (MLR) estimator [21].

\section{Results}

The descriptive statistics of the health-related quality of life (HRQOL) indicators at two measurement points and the correlation coefficients across the time points are presented in Table 2. We found that all study variables were approximately normally distributed, as the coefficients of skewness and kurtosis were within the range of \pm 2 [22]. Most HRQOL indicators were significantly positively interrelated across the timepoints, except for the pre-operative role limitations due to emotional problems (RE), which was not linked to the RE at 5-year-follow-up.

\section{Changes in health-related quality of life indicators}

The multivariate latent change analysis with gender as a control variable yielded a very good model fit $\left(\chi^{2}\right.$ $(7)=3.36, \quad p=0.850, \quad$ CFI $/ \mathrm{TLI}=1.000 / 1.062, \quad$ RMSEA $[90 \% \mathrm{CI}]=0.000[0.000,0.047], \quad \mathrm{SRMR}=0.010)$. The results indicated significant $(p<0.001)$ positive changes in physical functioning $(\mathrm{PF})$, mental health $(\mathrm{MH})$, vitality (VT), and social functioning (SF) over time. No changes were observed in general health $(\mathrm{GH} ; p=0.067)$, bodily pain (BP; $p=0.248)$, absence of role limitations due to physical problems (RP; $p=0.686$ ), and absence of role limitations due to emotional problems (RE; $p=0.169$ ) over the period of 5 years after the heart surgery (see Table 3). For all HRQOL indicators, we found significant negative links $(p<0.001)$ between intercepts and slopes (see Table 3), indicating that lower levels of $\mathrm{GH}$, $\mathrm{PF}, \mathrm{BP}, \mathrm{MH}, \mathrm{RP}, \mathrm{RE}, \mathrm{VT}$, and SF before surgery were associated with larger increases in these indicators. Significant gender effects were found on intercepts of $\mathrm{GH}$ $\left(\beta_{\text {intercept }}=0.17, p=0.003\right), \operatorname{PF}\left(\beta_{\text {intercept }}=0.19, p<0.001\right)$, BP $\quad\left(\beta_{\text {intercept }}=0.19, \quad p<0.001\right), \quad \mathrm{MH} \quad\left(\beta_{\text {intercept }}=0.14\right.$, $p=0.006), \quad$ VT $\quad\left(\beta_{\text {intercept }}=0.24, \quad p<0.001\right), \quad$ and SF $\left(\beta_{\text {intercept }}=0.11, p=0.019\right)$, indicating higher scores of these HRQOL indicators before heart surgery in men, compared to women. Further, significant gender effects 
Table 2 Descriptive statistics and correlations of HRQOL indicators across two measurement points

\begin{tabular}{|c|c|c|c|c|c|c|}
\hline & \multicolumn{2}{|c|}{ Pre-surgery (T1) } & \multicolumn{2}{|c|}{ 5-year follow-up (T2) } & \multirow[t]{2}{*}{$t(d f)$} & \multirow[t]{2}{*}{$r$} \\
\hline & $M(S D)$ & $\gamma_{1}, \gamma_{2}$ & $M(S D)$ & $\gamma_{1}, \gamma_{2}$ & & \\
\hline General health & $48.08(16.36)$ & $0.22 / 0.34$ & $50.70(19.79)$ & $0.08 /-0.15$ & $-1.73(199)$ & $0.31^{* * *}$ \\
\hline Physical functioning & $62.10(24.31)$ & $-0.74 /-0.09$ & $76.91(22.39)$ & $-1.25 / 1.16$ & $-8.23(204)^{* * *}$ & $0.39^{* * *}$ \\
\hline Bodily pain & $58.35(24.12)$ & $0.06 /-0.66$ & $60.84(29.25)$ & $-0.02 /-0.95$ & $-1.07(206)$ & $0.22^{* *}$ \\
\hline Mental health & $64.84(17.76)$ & $0.03 /-0.97$ & $73.08(17.17)$ & $-0.35 /-0.44$ & $-5.77(202)^{* * *}$ & $0.32^{* * *}$ \\
\hline Role limitations (physical) & $66.29(16.80)$ & $0.62 /-0.88$ & $69.34(28.70)$ & $-0.56 /-0.73$ & $-1.28(197)$ & -0.01 \\
\hline Role limitations (emotional) & $73.27(21.06)$ & $0.13 /-1.55$ & $76.23(25.86)$ & $-0.70 /-0.66$ & $-1.42(206)$ & $0.20^{* *}$ \\
\hline Vitality & $57.58(19.39)$ & $-0.01 /-0.48$ & $63.64(19.48)$ & $-0.11 /-0.83$ & $-3.74(197)^{* * *}$ & $0.31^{* * *}$ \\
\hline Social functioning & $64.43(26.47)$ & $-0.33 /-0.77$ & $81.83(24.86)$ & $-1.29 / 0.88$ & $-7.69(203)^{* * *}$ & $0.21^{* *}$ \\
\hline
\end{tabular}

$M=$ mean, $S D=$ standard deviation, $\gamma_{1}=$ skewness, $\gamma_{2}=$ kurtosis

${ }^{* *} p<0.01,{ }^{* * *} p<0.001$

Table 3 Pearson r correlations of intercepts and slopes of study variables

\begin{tabular}{|c|c|c|c|c|c|c|c|c|c|}
\hline \multicolumn{2}{|c|}{ Intercepts } & \multicolumn{8}{|l|}{ Slopes } \\
\hline & & 1 & 2 & 3 & 4 & 5 & 6 & 7 & 8 \\
\hline 1 & General health & $-0.48^{* * *}$ & $-0.20^{* * *}$ & -0.07 & -0.12 & 0.11 & -0.02 & $-0.21^{* *}$ & -0.09 \\
\hline 2 & Physical functioning & -0.07 & $-0.57^{* * *}$ & -0.07 & -0.08 & 0.15 & $-0.25^{* * *}$ & $-0.28^{* * *}$ & $-0.28^{* * *}$ \\
\hline 3 & Bodily pain & 0.12 & $-0.22^{* *}$ & $-0.55^{* * *}$ & $-0.14^{*}$ & $0.14^{*}$ & -0.05 & $-0.30^{* * *}$ & $-0.28^{* * *}$ \\
\hline 4 & Mental health & -0.06 & -0.05 & $-0.14^{*}$ & $-0.60^{* * *}$ & 0.05 & -0.07 & $-0.29 * * *$ & $-0.27^{* *}$ \\
\hline 5 & Role limitations (physical) & -0.06 & -0.09 & -0.08 & -0.11 & $-0.51^{* * *}$ & $-0.15^{*}$ & $-0.19^{* *}$ & -0.12 \\
\hline 6 & Role limitations (emotional) & -0.09 & $-0.25^{* * *}$ & -0.09 & $-0.22^{* *}$ & 0.08 & $-0.52^{* * *}$ & $-0.28^{* * *}$ & $-0.18^{*}$ \\
\hline 7 & Vitality & -0.03 & $-0.20^{* *}$ & $-0.18^{* *}$ & $-0.27^{* * *}$ & $0.13^{*}$ & -0.04 & $-0.59^{* * *}$ & $-0.23^{* *}$ \\
\hline 8 & Social functioning & 0.12 & $-0.15^{*}$ & -0.14 & -0.13 & $-0.16^{*}$ & -0.04 & $-0.24^{* *}$ & $-0.67^{* * *}$ \\
\hline
\end{tabular}

${ }^{*} p<0.05,{ }^{* *} p<0.01,{ }^{* * *} p<0.001$

were found on slopes of PF $\left(\beta_{\text {slope }}=-0.13, p=0.016\right)$ and $\mathrm{RE}\left(\beta_{\text {slope }}=0.16, p=0.004\right)$, indicating larger increases in physical functioning for men, compared to women and larger decreases in role limitation due to emotional problems in women, compared to men.

\section{Moderators of initial levels and changes in health-related quality of life indicators}

The intercepts and slopes of the Health-Related Quality of Life (HRQOL) Indicators in the groups representing significant moderators are presented in Table 4. Out of five investigated preoperative factors, only the arrhythmia was found to be a significant moderator of the latent change model of HRQOL indicators $\left(\Delta \chi^{2}(16)=29.26\right.$, $p=0.022, \quad \Delta \mathrm{CFI}=0.011, \quad \triangle \mathrm{RMSEA}=0.030)$ with no differences in free versus fixed intercept and slope parameter models testing the moderating effects of dyslipidemia $\left(\Delta \chi^{2}(16)=17.22, \quad p=0.372, \quad \Delta \mathrm{CFI}=0.001\right.$, $\triangle \mathrm{RMSEA}=0.012), \quad$ hypertension $\quad\left(\Delta \chi^{2}(16)=21.83\right.$, $p=0.149, \quad \Delta \mathrm{CFI}=0.002, \quad \Delta \mathrm{RMSEA}=0.028)$, reduced left-ventricular ejection fraction $\left(\Delta \chi^{2}(16)=12.11\right.$, $p=0.736, \Delta \mathrm{CFI}=0.000, \Delta \mathrm{RMSEA}=0.000)$, and higher EuroScore II $\left(\Delta \mathrm{X}^{2}(16)=19.32, p=0.252, \Delta \mathrm{CFI}=0.002\right.$, $\triangle \mathrm{RMSEA}=0.026)$. The model with all free parameters among arrythmia versus no arrythmia group yielded a very good model fit $\left(\chi^{2}(14)=16.47, p=0.285, \mathrm{CFI} /\right.$ $\mathrm{TLI}=0.998 / 0.962, \quad \mathrm{RMSEA} \quad[90 \% \mathrm{CI}]=0.041 \quad[0.000$, $0.107], S R M R=0.024)$. The Wald $X^{2}$ analyses indicated significant differences in initial rates of vitality (VT) $\left(\chi^{2}\right.$ $(1)=10.71, p=0.001)$ and social functioning (SF) $\left(\chi^{2}\right.$ $(1)=4.03, p=0.045)$ between the two groups with higher scores of both HRQOL indicators in the no arrhythmia group, compared to the arrhythmia group. No differences between groups were found in terms of change parameters, indicating lower levels of VT and SF in the arrhythmia group at 5 years follow-up after the heart surgery.

The type of surgery (coronary artery bypass graft (CABG) versus complex/valve surgery) was also found to be a significant moderator of the latent change model of HRQOL indicators $\left(\Delta \chi^{2}(16)=30.866, p=0.014\right.$, $\triangle \mathrm{CFI}=0.011, \Delta \mathrm{RMSEA}=0.065)$. The model with all free parameters among the two groups yielded a 
Table 4 Intercepts and slopes of HRQOL indicators in the full sample and the groups of significant moderators

\begin{tabular}{|c|c|c|c|c|c|c|c|c|}
\hline & \multicolumn{2}{|c|}{$\begin{array}{l}\text { Full sample } \\
(N=210)\end{array}$} & \multicolumn{2}{|c|}{$\begin{array}{l}\text { Arrhythmia (no/yes) } \\
(n=167 / 43)\end{array}$} & \multicolumn{2}{|c|}{ CABG (no/yes) $(n=74 / 136)$} & \multicolumn{2}{|c|}{$\begin{array}{l}\text { Higher education (no/yes) } \\
(n=146 / 64)\end{array}$} \\
\hline & $M_{\text {intercept }}$ & $M_{\text {slope }}$ & $M_{\text {intercept }}$ & $M_{\text {slope }}$ & $M_{\text {intercept }}$ & $M_{\text {slope }}$ & $M_{\text {intercept }}$ & $M_{\text {slope }}$ \\
\hline General health & 43.55 & 2.69 & $44.45 / 43.70$ & $2.27 / 3.36$ & $43.20 / 44.49$ & $6.76^{\mathrm{a} * *} / 0.41^{\mathrm{b}}$ & $44.20 / 42.21$ & $1.75 / 4.39$ \\
\hline Physical functioning & 53.16 & $19.79^{* * *}$ & $54.94 / 48.38$ & $18.23^{* * *} / 24.45^{* * *}$ & $56.07 / 50.52$ & $19.99^{* * *} / 20.07^{* * *}$ & $49.70^{\mathrm{a}} / 63.96^{\mathrm{b}}$ & $24.99^{a * * *} / 6.49^{b}$ \\
\hline Bodily pain & 51.16 & 2.69 & $52.06 / 50.60$ & $4.07 /-2.80$ & $54.06 / 50.22$ & $-0.94 / 4.71$ & $49.14 / 59.60$ & $3.81 /-0.18$ \\
\hline Mental health & 60.68 & $8.40^{* * *}$ & $61.85 / 57.36$ & $8.93^{* * *} / 6.53^{*}$ & $59.20 / 63.96$ & $7.70^{* *} / 8.84^{* * *}$ & $59.12 / 64.91$ & $9.38^{* * *} / 6.31^{* *}$ \\
\hline Role limitations (physical) & 66.17 & 1.48 & $66.61 / 64.85$ & $-2.46 / 3.54$ & $66.26 / 66.17$ & $5.33 /-6.77$ & $64.86 / 68.89$ & $2.03 /-8.13$ \\
\hline Role limitations (emotional) & 73.03 & -4.47 & $74.33 / 67.99$ & $-4.73 /-1.72$ & $76.81 / 71.09$ & $-9.25 * / 0.11$ & $69.77^{a} / 80.18^{b}$ & $-3.81 /-7.11$ \\
\hline Vitality & 50.36 & $6.30^{* * *}$ & $53.86^{\mathrm{a}} / 40.66^{\mathrm{b}}$ & $6.10^{* *} / 6.80^{*}$ & $50.91 / 48.93$ & $8.28^{* *} / 5.21^{* *}$ & $49.41 / 52.38$ & $8.39^{\mathrm{a} * * *} / 1.71^{\mathrm{b}}$ \\
\hline Social functioning & 59.68 & $17.27^{* * *}$ & $62.95^{a} / 50.39^{b}$ & $15.68^{* * *} / 23.30^{* * *}$ & $61.64 / 59.16$ & $13.81^{* * *} / 19.10^{* * *}$ & $58.76 / 63.81$ & $17.35^{* * *} / 17.49^{* * *}$ \\
\hline
\end{tabular}

$M=$ mean, ${ }^{*} p<0.05,{ }^{* *} p<0.01,{ }^{* * *} p<0.001$

a,b Different letters indicate statistically significant differences among groups

very good model fit $\left(\chi^{2}(14)=12.36, p=0.577\right.$, CFI/ $\mathrm{TLI}=1.000 / 1.027, \quad$ RMSEA $[90 \% \mathrm{CI}]=0.000 \quad[0.000$, $0.084]$, SRMR $=0.022$ ). The Wald $\chi^{2}$ test indicated significant differences in change rates of general health $(\mathrm{GH})\left(\mathrm{X}^{2}(1)=4.41, p=0.036\right)$ among the CABG versus other types of surgery groups. The complex/valve group reported a significant increase in $\mathrm{GH}$, while change in $\mathrm{GH}$ was not observed in the CABG group. However, complex/valve group reported a significant decrease in absence of role limitations due to emotional problems (RE) with no changes of RE in CABG group over the period of 5 years after the heart surgery. It should be noted that the difference in the change rates of RE among the two groups was not supported by the Wald $\chi^{2}$ test $\left(\chi^{2}\right.$ $(1)=2.22, p=0.137)$.

Older age $(>=70$ years versus $<70$ years old) was found to have no moderating effects on the latent change model of HRQOL indicators $\left(\Delta \mathrm{X}^{2}(16)=13.96\right.$, $p=0.602, \quad \Delta \mathrm{CFI}=0.000, \quad \Delta \mathrm{RMSEA}=0.000) \quad$ when the higher education yielded a significant moderating effects $\left(\Delta \mathrm{X}^{2}(16)=29.64, p=0.020, \Delta \mathrm{CFI}=0.009\right.$, $\triangle$ RMSEA $=0.060)$. The model with all free parameters among higher education versus other type of education groups yielded a very good model fit $\left(\chi^{2}(14)=11.56\right.$, $p=0.642, \quad$ CFI $/$ TLI $=1.000 / 1.040, \quad$ RMSEA $\quad[90 \%$ $\mathrm{CI}]=0.000[0.000,0.079], \mathrm{SRMR}=0.021$ ). The Wald $\chi^{2}$ analyses indicated significant differences in change rates of physical functioning (PF) $\left(\chi^{2}(1)=11.52, p<0.001\right)$ and vitality $(\mathrm{VT})\left(\mathrm{X}^{2}(1)=4.05, p=0.044\right)$ between two groups with the significant increase of both HRQOL indicators in the lower education group and stability in the higher education group. However, the higher education group reported significantly higher scores of PF before the surgery, compared to the lower education group $\left(x^{2}\right.$ $(1)=3.97, p=0.046)$, while initial VT scores were found to be equal among groups. However, the lower education group reported significantly lower scores in role limitations due to emotional problems (RE) before the surgery, compared to the higher education group $\left(\chi^{2}(1)=10.56\right.$, $p=0.001$ ) with no differences in change rates between groups, indicating higher levels of RE in the higher education group at 5-year follow-up.

\section{Discussion}

The main aim of the current study was to assess changes in the physical and mental health of patients following cardiac surgery over a period of five years after the surgery. The results from this study support previous research $[1,5,8,23]$ that cardiac surgery may improve functional mobility, can have a long-lasting positive effect on social independence and overall higher quality of life. Based on the findings of the current study, patients experienced HRQOL as significantly improved 5 years after cardiac surgery, this reflected by increases in selfassessed HRQOL domains, in particular, physical health, mental health, vitality, and social functioning on the SF-36. It is worth mentioning, that our results support a the link between improvement in physical condition after heart surgery and higher self-perceived mental and social functioning over five years. These results suggest that the integration of mental and physical health assessment could result in a more holistic approach in the understanding of postoperative recovery.

Longitudinal studies assessing the long-term trajectories of postoperative HRQOL highlight the effects of natural aging [10]. In our study, however, HRQOL changes were observed in both elderly and younger patients. The more significant improvement in HRQOL 5 years after surgery was achieved in patients with lower preoperative quality of life, meaning that those with relatively better preoperative HRQOL may underestimate the positive effects of the surgery. This paradoxical effect 
in deterioration of health perception despite favorable surgical results was observed by previous authors [24, 25]. Immediate postoperative deterioration in HRQOL might be a result of increased pain, reduced mobility, and increased social dependence. However, the long-term interactions between self-perceived preoperative and postoperative health could be related to overall illness beliefs, which play an important role in recovery, engagement in follow-up, and postoperative rehabilitation [26, 27]. We suggest that identification and addressing of patient maladaptive illness beliefs before surgery could positively affect outcomes and perception of recovery.

Previous studies exploring associations between patient education level and post-procedural outcomes concluded that education level and HRQOL have an inverse relationship [23]. Similarly, in our study, postoperatively overall improvement in the perception of health was more prominent in patients with lower education levels. Our data suggest that patients with higher education experienced less restriction in social activities because of emotional problems preoperatively (RE). We suggest that patients with higher education had better coping skills in everyday activities and therefore were functioning better before cardiac surgery and experienced fewer changes in HRQOL at a 5-year-follow-up. This suggestion is supported by significantly higher HRQOL values in the higher education subgroup pre-operatively. The role of education should be evaluated in the context of other socioeconomic variables such as income, living conditions, or employment. Further research is needed to determine the impact of educational level on outcomes.

Our findings are consistent with previous reports indicating substantial gender-related disparity in physical HRQOL both before and after cardiac surgery with women having lower scores in several HRQOL subdomains [16]. We controlled for gender in analyzing change and predictors of HRQOL in our study, however, due to a rather small proportion of female participants in our study, we did not examine the effects of gender on HRQOL. Future studies should explore the moderator effects of gender on long-term HRQOL.

Our study suggests that patients with increased preoperative risk, as evidenced by the high Euroscore II values, underwent postoperative recovery as successfully as the lower risk group, and showed significant improvement in their self-perceived physical health, mental and social functioning. Patients after low-risk CABG surgery experienced no improvement in general health $(\mathrm{GH})$, while improvement in $\mathrm{GH}$ was observed in patients after higher-risk surgeries. Further research is needed to determine the factors that may assist successful recovery in high-risk patients and influence the perception of wellbeing postoperatively. We have also identified some differences in HRQOL in patients with the presence of atrial fibrillation (AF). In particular, we found lower levels of vitality and social functioning in patients with arrhythmia at baseline and five years after the surgery. Studies using HRQOL outcomes confirm that patients diagnosed with AF experience more functional limitations, depression, anxiety, and distress [27]. Lower HRQOL and more mental health problems might contribute to reduced adherence to medications and engagement in physiotherapy, and eventually have an impact on physical recovery after surgery [28]. The mutual relation between anxiety and AF initiation and progression remains ambiguous. Cochrane systematic review suggests comprehensive behavioral interventions for patients with atrial fibrillation [27]. Our data demonstrated that more complex strategies should be implemented to enhance the functional recovery of patients with $\mathrm{AF}$, complemented by the implementation of educational and behavioral interventions, in particular self-care and self-management programs.

\section{Limitations}

This is one of the first studies to explore long-term HRQOL in a 5-year prospective study. While study findings are promising several limitations needs to be addressed. First, the current study sample was restricted to the collection of data in a single site and a comparably small sample size that limited the possibility to identify the subgroups of patients with different patterns of clinical outcomes. Replication of study in larger samples and applying the person-oriented approach in the analyses is needed in the future. Second, around 27\% dropout rate could have impacted our findings, with patients with more severe medical conditions and lower HRQOL potentially among participants who did not respond and participate. Third, we rely on self-reported HRQOL in our study. While the SF-36 is a widely used measure for HRQOL additional medical examination, some recent studies indicated that other measures could be more appropriate for assessing specific patient-reported outcomes and may be more responsive to change in HRQOL $[29,30]$. Therefore, at follow-up the inclusion of other specific patient-reported outcomes could have provided more insight into the study.

\section{Conclusions}

Our findings demonstrated a positive change in HRQOL 5 years after cardiac surgery. Overall in our study sample, HRQOL improved from baseline to five years after cardiac surgery. Moreover, an improvement was more significant in patients demonstrating lower rates of SF-36 before the surgery. The study provides insights for patient care as it shows that multiple factors, including 
psychosocial functioning, contribute to recovery and quality of life after medical procedures, and improvement cannot be predicted solely by the clinical status of the patient or the medical procedures.

\section{Authors' contributions}

DG: Investigation; Data curation; Writing—review and editing. IN: Conceptualization; Writing —original draft; Writing—review and editing. EK: Conceptualization; Supervision; Writing —review and editing. ITK: Formal analysis; Writing —original draft; Writing — review and editing. SK: Data curation: Writing — review and editing. DR: Investigation; Writing — review and editing. JS: Writing - review and editing. All authors read and approved the final manuscript.

\section{Funding}

The authors received no funding for this study.

\section{Availability of data and materials}

Data supporting the findings of the study could be obtained from the corresponding author upon request.

\section{Declarations}

Ethics approval and consent to participate

The study was approved by the Regional Bioethics Committee.

\section{Consent for publication}

Written informed consent was obtained from each patient at inclusion.

\section{Competing interests}

The authors have no conflict of interest to disclose.

\section{Author details}

${ }^{1}$ Clinic of Anaesthesiology and Intensive Care, Institute of Clinical Medicine, Faculty of Medicine, Vilnius University, Vilnius, Lithuania. ${ }^{2}$ Centre for Psychotraumatology, Institute of Psychology, Vilnius University, Vilnius, Lithuania.

\section{Received: 9 February 2021 Accepted: 8 August 2021}

Published online: 17 August 2021

\section{References}

1. Tully PJ. Quality-of-life measures for cardiac surgery practice and research: a review and primer. J Extra Corpor Technol. 2013;45:8-15.

2. Gaudino M, Girola F, Piscitelli M, et al. Long-term survival and quality of life of patients with prolonged postoperative intensive care unit stay: unmasking an apparent success. JThorac Cardiovasc Surg. 2007;134:465-9.

3. Gjeilo KH, Stenseth R, Wahba A, et al. Long-term health-related quality of life and survival after cardiac surgery: a prospective study. JThorac Cardiovasc Surg. 2018;156:2183-2190.e2.

4. Gierlaszyńska K, Pudlo R, Jaworska I, et al. Tools for assessing quality of life in cardiology and cardiac surgery. Kardiochirurgia i Torakochirurgia Pol JThorac Cardiovasc Surg. 2016;13:78-82.

5. Rijnhart-De Jong H, Haenen J, Bol Raap G, et al. Determinants of nonrecovery in physical health-related quality of life one year after cardiac surgery: a prospective single Centre observational study. J Cardiothorac Surg. 2020;15:1-9.

6. Thomson Mangnall $L$, Sibbritt DW, Fry M, et al. Health-related quality of life of patients after mechanical valve replacement surgery for rheumatic heart disease in a developing country. Heart Asia. 2014;6:172-8.

7. Rawashdeh RA, Alshraideh JA. Physiological and psychological determinants of quality of life for patients after cardiac surgery and the associated factors. Open J Nurs. 2019;09:1022-40.

8. Nedeljković UD, Krstić NM, Varagić-Marković SL, et al. Quality of life and functional capacity one year after coronary artery bypass graft surgery. Acta Chir lugosl. 2011;58:81-6.
9. Merkouris A, Apostolakis E, Pistolas D, et al. Quality of life after coronary artery bypass graft surgery in the elderly. Eur J Cardiovasc Nurs. 2009;8:74-81.

10. Perrotti A, Ecarnot F, Monaco F, et al. Quality of life 10 years after cardiac surgery in adults: a long-term follow-up study. Health Qual Life Outcomes. 2019;17:1-9.

11. Blokzijl F, DieperinkW, Keus F, et al. Cardiac rehabilitation for patients having cardiac surgery: a systematic review. J Cardiovasc Surg (Torino). 2018;59:817-29.

12. Brazier JE, Harper R, Jones NMB, et al. Validating the SF-36 health survey questionnaire: new outcome measure for primary care. Br Med J. 1992;305:160-4.

13. Staniute M, Brozaitiene J, Bunevicius R. Effects of social support and stressful life events on health-related quality of life in coronary artery disease patients. J Cardiovasc Nurs. 2013;28:83-9.

14. Chalmers J, Pullan M, Fabri B, et al. Validation of EuroSCORE II in a modern cohort of patients undergoing cardiac surgery. Eur J Cardio-thoracic Surg. 2013;43:688-94.

15. Duncan TE, Duncan SC, Strycker LA. An introduction to latent variable growth curve modeling: concepts, issues, and application. New York: Taylor \& Francis; 2013. https://doi.org/10.4324/9780203879962.

16. Norris CM, Spertus JA, Jensen L, et al. Sex and gender discrepancies in healthrelated quality of life outcomes among patients with established coronary artery disease. Circ Cardiovasc Qual Outcomes. 2008;1:123-30.

17. Sawatzky JAV, Naimark BJ. The coronary artery bypass graft surgery trajectory: gender differences revisited. Eur J Cardiovasc Nurs. 2009;8:302-8.

18. Satorra A, Bentler P. Is used as a chi-square test statistic with degrees of freedom equal to the difference on the number of independent parameters estimated under the models AdO and Adl. As in the case of the goodness-offit test, it is of interest to scale the statistic. Psychometrika. 2001;66:507-14.

19. Chen FF. Sensitivity of goodness of fit indexes to lack of measurement invariance. Struct Equ Model. 2007;14:464-504.

20. Kline RB. Principles and practice of structural equation modeling. Guilford publications; 2015

21. Muthén L, Muthén B. Mplus user's guide. 8th ed. Los Angeles: Muthén \& Muthén; 2017.

22. Gravetter F, Wallnau L. Essential statistics for the bevahioural sciences. Belmont: Wadsworth; 2014.

23. Lie I, Bunch EH, Smeby NA, et al. Patients' experiences with symptoms and needs in the early rehabilitation phase after coronary artery bypass grafting. Eur J Cardiovasc Nurs. 2012;11:14-24.

24. Norkienè I, Urbanaviciute I, Kezyte G, et al. Impact of pre-operative health-related quality of life on outcomes after heart surgery. ANZ I Surg. 2018;88:332-6.

25. Al-Ruzzeh S, Athanasiou T, Mangoush O, et al. Predictors of poor mid-term health related quality of life after primary isolated coronary artery bypass grafting surgery. Heart. 2005;91:1557-62.

26. Stafford L, Berk M, Jackson HJ. Are illness perceptions about coronary artery disease predictive of depression and quality of life outcomes? J Psychosom Res. 2009;66:211-20.

27. Clarkesmith DE, Pattison HM, Khaing PH, et al. Educational and behavioural interventions for anticoagulant therapy in patients with atrial fibrillation. Cochrane Database Syst Rev. 2017. https://doi.org/10.1002/14651858.CD008 600.pub3.

28. van Breugel HNAM, Parise O, Nieman FHM, et al. Does sinus rhythm conversion after cardiac surgery affect postoperative health- related quality of life? J Cardiothorac Surg. 2016;11:1-10

29. Rajati F, Feizi A, Tavakol K, et al. Comparative evaluation of health-related quality of life questionnaires in patients with heart failure undergoing cardiac rehabilitation: a psychometric study. Arch Phys Med Rehabil. 2016:97:1953-62.

30. Moshki M, Khajavi A, Vakilian F, et al. The content comparison of healthrelated quality of life measures in heart failure based on the international classification of functioning, disability, and health: a systematic review. J Cardiovasc Thorac Res. 2019;11:167-75.

\section{Publisher's Note}

Springer Nature remains neutral with regard to jurisdictional claims in published maps and institutional affiliations. 